Arch. Dis. Childh., 1963, 38, 454.

\title{
WEST INDIAN BABIES WITH MULTIPLE CONGENITAL DEFECTS*
}

BY

\author{
CLIFFORD G. PARSONS \\ From The Children's Hospital, Birmingham
}

(RECEIVED FOR PUBLICATION FEBRUARY 13, 1963)

In the autumn of 1958 and the early months of 1959 seven West Indian babies were brought to the Children's Hospital, Birmingham, suffering from cataract, congenital heart disease and microcephaly. By the end of January 1962, 25 infants with multiple congenital defects had been seen. The clinical features are summarized in Table 1.

* The substance of a paper presented at the Section of Paediatrics, Royal Society of Medicine, meeting in Birmingham in June 1962 to celebrate the centenary of the Children's Hospital.
The similarity of these cases suggested a common cause, and as eyes, head and heart were so frequently affected, inquiry was restricted to children who had at least two malformations of this triad (Table 2). This may have led to exclusion of babies with congenital defects due to the same cause, but occurring in isolation or in some other combination. A baby with bilateral cataract and a patent ductus arteriosus was omitted because, as the child died on the second day, it could not be proved that the open ductus was abnormal.

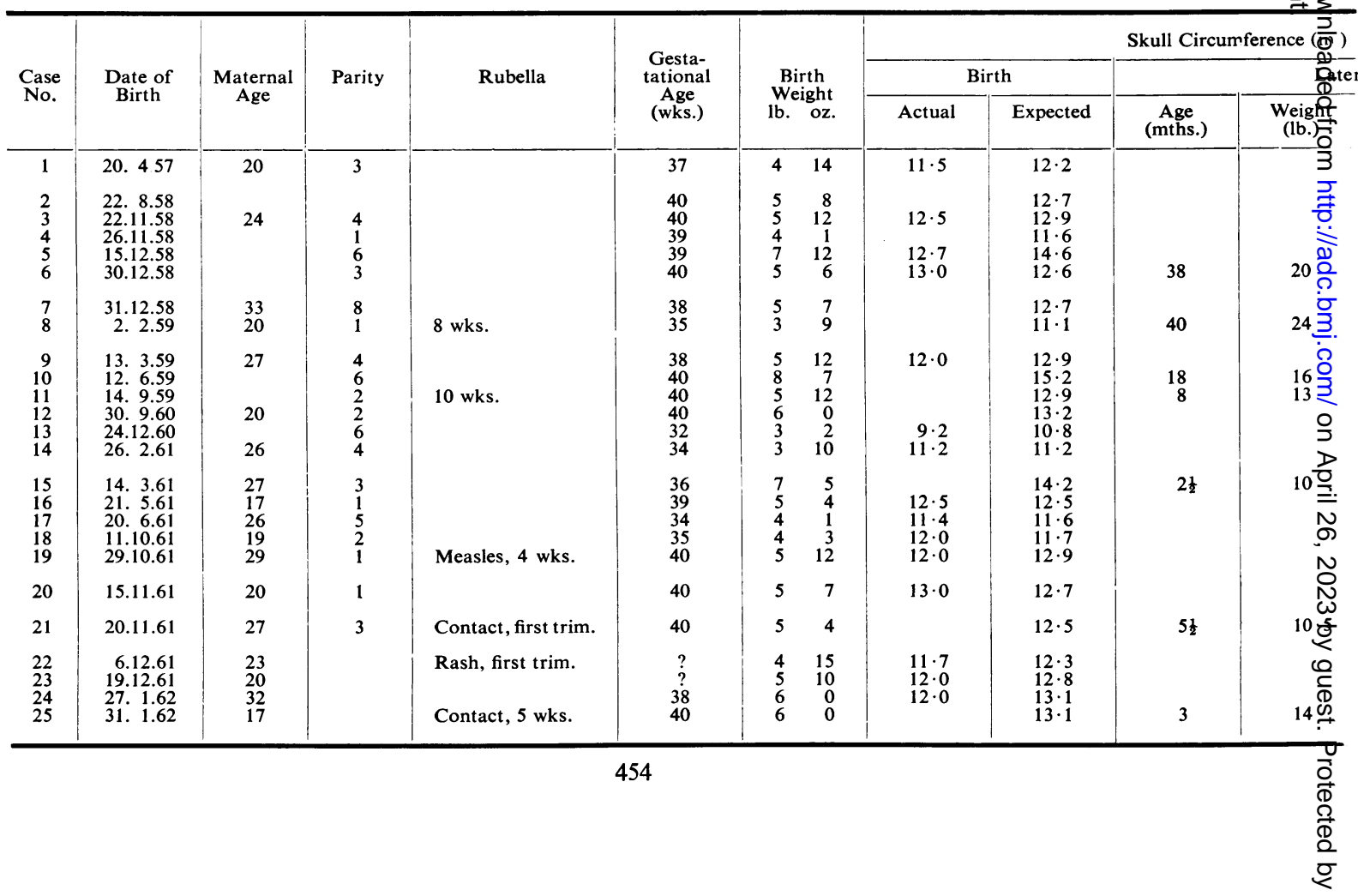




\section{Clinical Features}

Birth Weight. Only three babies exceeded $6 \mathrm{lb}$. $(2,721$ g.) at birth. In the remaining 22 cases birth weight was less than that expected for gestational age, although the observed weights lay within two standard deviations of the mean for that degree of maturity. Gestational ages were estimated by mothers and obstetricians to be between 32 and 40 weeks.

Size of Head. Measurements were recorded at birth in 15 cases, and of these six had skulls more than two standard deviations below the mean for their birth weight. Gestational ages were not estimated for two infants who were said to have small heads at birth. A 'small brain' was found at necropsy in another case. A mongol and two children with severe mental retardation had skull measurements within the normal range. Four babies measured for the first time only in later infancy had heads smaller than the means expected for their ages by more than twice the standard deviation.

Intelligence. This was difficult to assess in the early months of life, especially when sight was defective or hearing impaired. (Mr. George Dalton
TABLE 2

MAJOR MALFORMATIONS

\begin{tabular}{c|c|c|c}
\hline \multicolumn{3}{|c|}{ Summary of Findings in 25 Cases } \\
\cline { 2 - 3 } Head & Eye & Heart & Cases \\
\hline+ & + & + & 11 \\
+ & + & + & 4 \\
+ & + & + & 9
\end{tabular}

has confirmed that some of the older children have hearing defects, involving particularly higher frequencies.) Two mongols with autosomal trisomy21 , and four children who were considered to be severely retarded as they could not walk or talk at the age of 3 years, are included in the series. Electroencephalograms were taken occasionally to determine whether babies could hear or appreciate light, and in one retarded infant Dr. Bower reported an abnormal tracing suggesting 'a fairly gross cerebral lesion such as hydranencephaly'.

Eyes. Cataract was the commonest presenting feature (Fig. 1), and all children were examined by Mr. Martin Walker, Mr. Roper Hall or Mr. Crews. Mr. Roper Hall's comments on the eye changes may be summarized as follows. Cataract was unilateral

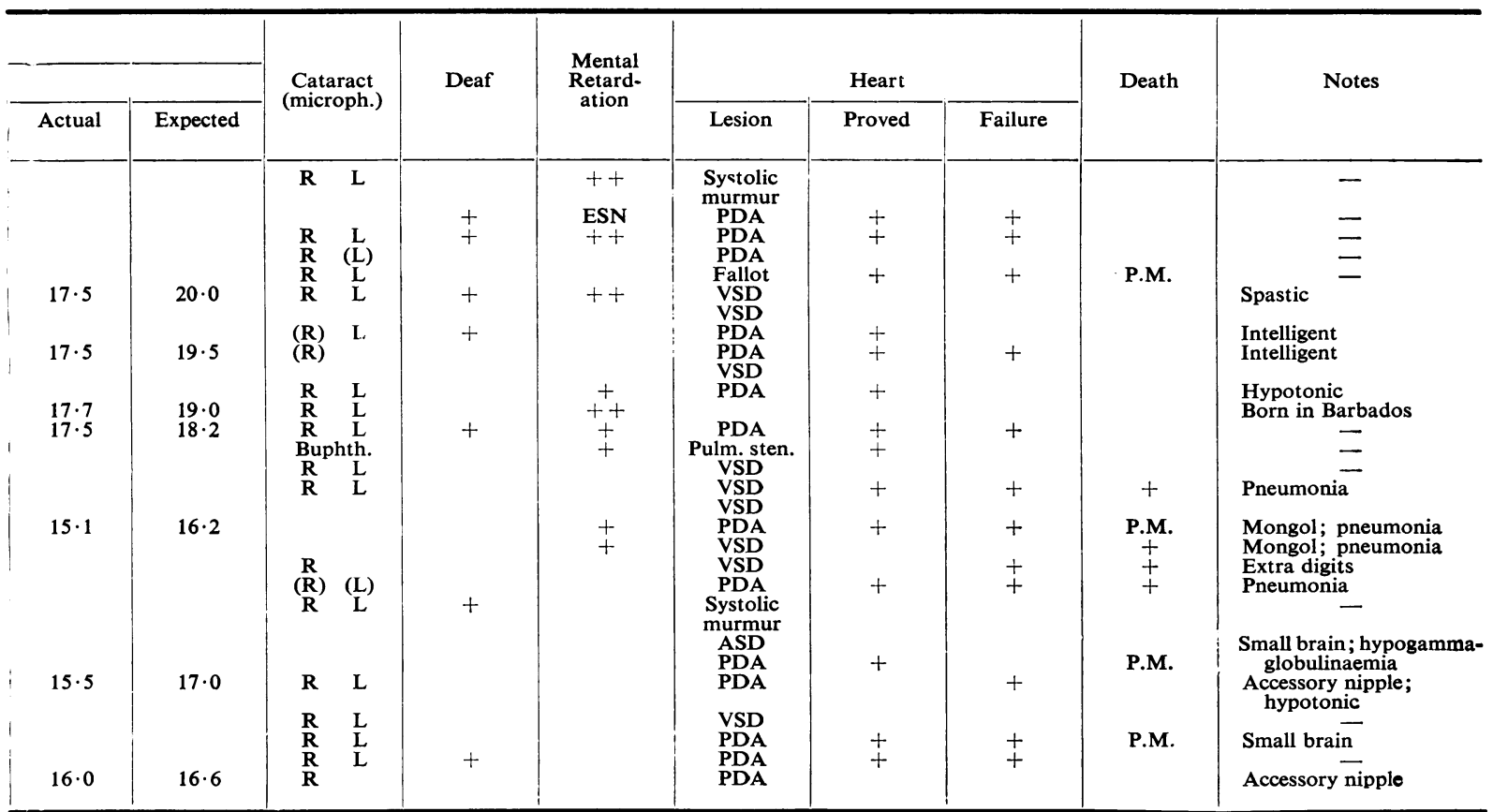




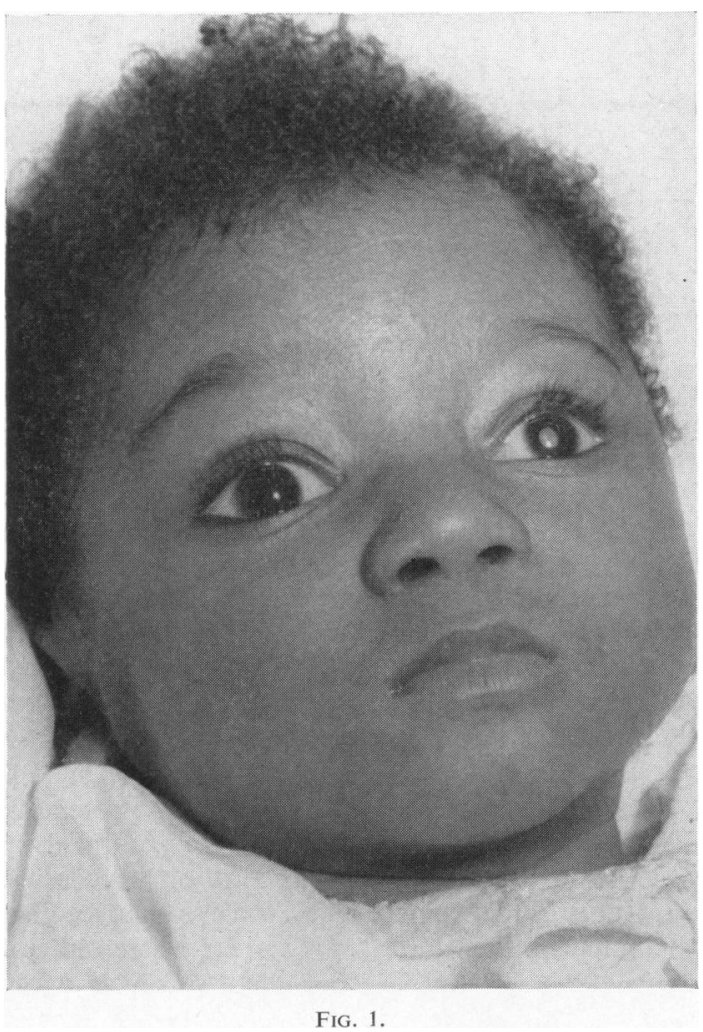

in three and bilateral in 17 cases, the lens being smaller than normal, with a dense white central opacity, a thinner smoky zone surrounding it, and a narrow peripheral ring of clear cortex through which a fundus reflex could just be detected. Nystagmus was usual, although not necessarily present in the early stages; it was observed in three babies who had unilateral cataracts. Two of these infants had pigmentary retinopathy, with small round or irregular masses of blackish or leaden grey pigment, especially in the area near to the macula. Professor Norman Ashton reported on

TABLE 3

\begin{tabular}{|c|c|c|c|c|}
\hline \multicolumn{5}{|c|}{ Abnormalities of Heart } \\
\hline Abnormality & Proved & Clinical & $\begin{array}{l}\text { Heart } \\
\text { Failure }\end{array}$ & Death \\
\hline $\begin{array}{l}\text { PDA } \ldots \\
\text { VSD . } \\
\text { PDA + VSD } \\
\text { PDA + ASD } \\
\text { Fallot } \ldots \\
\text { Pulmonary stenosis } \\
\text { Systolic murmur }\end{array}$ & $\begin{array}{l}7 \\
1 \\
3 \\
1 \\
1 \\
1\end{array}$ & $\begin{array}{l}3 \\
5\end{array}$ & $\begin{array}{l}8 \\
2 \\
1 \\
1\end{array}$ & $\begin{array}{l}2 \\
3 \\
1 \\
1 \\
1\end{array}$ \\
\hline Total & \multicolumn{2}{|c|}{24} & 12 & 8 \\
\hline
\end{tabular}

an eye removed from a baby after death at the age of 2 months.

'There is a peculiar redundancy and unfolding of the retina at the ora serrata. The most striking change ... is a total and complete loss of the sensory epithelium. The retina is in situ and these cells have been replaced by granular amorphous material. In some cases the retina is slightly elevated by this material and in such areas there is a tendency to globular formation. Discrete foci of pigment epithelial proliferation are seen throughout the eye.'

Eyes affected by cataract were sometimes small. Mr. Crews observed that in children with cataracts, sensitivity to mydriatics was liable to decrease with age, the iris becoming almost rigid after a few months. One child had bilateral buphthalmos.

Heart. Twenty-four children had congenital heart disease, and in 12 this was the presenting feature (Table 3). Diagnosis was said to be 'proved' after cardiac catheterization, angiocardiography, operation or necropsy, but children with "clinical evidence' of persistent ductus arteriosus or septal defect had considerable left-to-right shunts, and will certainly require further investigation and treatment. Five babies with persistent ductus arteriosus have already been treated surgically without mortality. Twelve infants had heart failure, and eight babies died in their first year, four as a result of pneumonia and the remainder from heart failure.

Additional Defects. Other defects observed occasionally included spasticity, hypotonia, accessory nipples, and supernumerary digits. One child had hypogammaglobulinaemia which may have been of congenital origin (albumin 4.6, globulin 1:6, $\alpha_{1} 0 \cdot 22, \alpha_{2} 0.60, \beta 0.62, \gamma 0.16 \mathrm{~g} . / 100 \mathrm{ml}$.).

\section{Cause of the Defects}

Information obtained by retrospective inquiry is likely to be incomplete and inaccurate. As far as possible the effects of syphilis, toxoplasmosis and drugs in early pregnancy have been eliminated. Chromosomal studies by Dr. J. Edwards have been negative except in two mongols. Maternal age or parity had no recognizable influence on incidence.

Many multiparous mothers had had normal children in the West Indies or in England before giving birth to the affected infant, and some have had normal babies since. In all cases the mother was in England for the first three months of the relevant pregnancy, but one child was born in Barbados.

Circumstantial evidence suggests that the underlying cause is maternal infection, probably rubella. 
(1) The first seven cases were born within a short period and came from a small area; one mother had had rubella in the first trimester. A batch of nine cases occurred at the end of 1961 and early in 1962; four mothers gave a suggestive history. Epidemics of rubella usually occur early in the year.

(2) Two consultant physicians confirmed that a woman was suffering from rubella during the eighth week of pregnancy. In three other cases a suspicious illness, with a rash, occurred during the first trimester, and two women were in contact with rubella early in pregnancy, although they did not develop the disease. Contact is recognized as a cause of the syndrome (Gregg, Beavis, Heseltine, Machin, Vickery and Meyers, 1945; Swan, 1949; Lundström, 1952).

(3) The clinical features noted in affected babies resembled those observed after maternal rubella. A low birth weight is usual. Microcephaly occurred in 65 of 111 cases reviewed by Swan in 1949, but only once in a prospective survey by Pitt, Lewis, Sims, Dods, Anderson and Wall in 1961, and not at all in the extensive prospective study organized by the Ministry of Health in England (Manson, Logan and Loy, 1960). Swan recorded mongolism after rubella, and it has been suggested that deafness, often unilateral and incomplete, is the commonest consequence of infection (Jackson and Fisch, 1958). The characteristic cataract was said by Gregg (1941) to be morphologically unlike any other type of congenital or developmental cataract. Microphthalmos and nystagmus sometimes occurred in association with cataract, but retinopathy has been less frequently recognized, being mentioned only once by Gregg and once by Swan (1949), but the condition may not always be recognizable with an ophthalmoscope. Buphthalmos has been described as a sequel to rubella. Many types of congenital heart disease have been reported, but persistent ductus arteriosus and ventricular septal defect are commonest (Stuckey, 1956).

\section{Incidence}

Maternal rubella in the first three months of pregnancy may be the cause of one or more congenital malformations but is rarely followed by a triad of major defects, involving head, eye and heart. A retrospective survey from Australia (Swan and Tostevin, 1946) referred to 64 infected mothers who gave birth to one baby with this triad and eight with defects of both heart and eye. The New South Wales report (Gregg et al., 1945) is more difficult to analyse: there were 99 deaf mutes and 10 children with eye and heart damage. 'A degree of microcephaly' was common, but only seven
TABLE 4

WEST INDIANS BORN IN BIRMINGHAM, 1958-1961

\begin{tabular}{|c|c|c|}
\hline \multicolumn{3}{|c|}{ (Total related births, 5,095 ) } \\
\hline Malformation & $\begin{array}{l}\text { Affected } \\
\text { Children }\end{array}$ & $\begin{array}{c}\text { Incidence } \\
\text { per } 1,000 \\
\text { Total Births }\end{array}$ \\
\hline $\begin{array}{l}\text { Head, eye, heart } \\
\text { Head, } \\
\text { Eye, heart }\end{array}$ & $\begin{array}{r}10 \\
3 \\
6\end{array}$ & $\begin{array}{l}1 \cdot 96 \\
0.59 \\
1 \cdot 18\end{array}$ \\
\hline $\begin{array}{l}\text { Total congenital heart } \\
\text { (complicated) }\end{array}$ & 19 & $3 \cdot 73$ \\
\hline
\end{tabular}

children were 'greatly below average' and of these six had heart disease. The Ministry of Health prospective survey in this country (Manson et al., 1960) reported 202 exposures, one triad and five children with lesions of heart and eye; a similar investigation in Australia (Pitt et al., 1961) recorded 61 exposures, one triad and two children with heart and eye affected.

The incidence of multiple congenital defects in babies born during the period 1958-1961 to West Indian parents resident within the city boundary is given in Table 4. Separate registration of West Indian births was first introduced in Birmingham in 1958 and numbers for that year are not strictly accurate, although this is unlikely to exert a noteworthy effect on an estimate of incidence. 5,095 births were recorded; 19 babies had multiple defects, 10 with the triad and six with lesions of heart and eye. No information is available about the frequency of rubella.

These figures may be compared with those obtained from a survey of births in Birmingham during 1952, no infant with congenital heart disease and cataract being noted amongst 56,760 related births (McKeown and Record, 1960; Leck, 1961).

In the West Indies the population drained by Kingston hospitals is much the same size as that of Birmingham, a million and a half. Dr. Smith Read, paediatrician at Victoria Jubilee Hospital, where approximately 12,000 babies are delivered yearly, saw only four babies with cataract, microcephaly and heart disease in a period of three years. She agrees with the views expressed by Dr. Degazon, ophthalmologist at Kingston Public Hospital, and with Dr. Back, paediatrician at University College Hospital, that in the West Indies infantile cataract is rarely due to rubella and that German measles is uncommon.

\section{Conclusions}

Twenty-four West Indian babies with multiple congenital abnormalities have been seen in the Midlands in a period of three and a half years, and 
similar cases have been observed in the Hackney area of London (R. J. K. Brown, 1962, personal communication). Immigrants from the West Indies may be exposed to rubella for the first time when they enter this country. The attack rate is difficult to assess as the disease is so easily overlooked. Constitutional symptoms may be slight and the fleeting rash may be hidden by a dark skin, but foetal damage is not dependent on the severity of the mother's infection (Gregg et al., 1945), and the clinical features exhibited by the babies are strongly suggestive of maternal rubella. The tendency of West Indian babies to multiple severe defects is noteworthy.

I am grateful to those mentioned in the text, to paediatricians in the Midlands who have supplied me with much information about patients, to Dr. D. F. Mahon, Professor T. McKeown, Dr. R. G. Record, Dr. John Waterhouse, and many others, for their help.
REFERENCES

Gregg, N. M. (1941). Congenital cataract following German measles in the mother. Trans. ophthal. Soc. Aust., 3, 35.

- Beavis, W. R., Heseltine, M., Machin, A. E., Vickery, D. and Meyers, E. (1945). The occurrence of congenital defects in children following maternal rubella during pregnancy. Med. $J$. Aust., 2, 122.

Jackson, A. D. M. and Fisch, L. (1958). Deafness following maternal rubella: results of a prospective investigation. Lancet, 2,1241 .

Leck. I. M. (1961) Malformations in a population observed for five years after birth. M.D. thesis, University of Birmingham.

Lundström, R. (1952). Rubella during pregnancy; its effects upon perinatal mortality, the incidence of congenital abnormalities and immaturity. Acta paediat. (Uppsala), 41, 583.

McKeown, T. and Record, R. G. (1960). In Ciba Foundation Symposium on Congenital Malformations, p. 2. Churchill, Sondon.

Manson, M. M., Logan, W. P. D. and Loy, R. M. (1960). Rubella and other virus infections during pregnancy. Ministry of Health and other virus infections during pregnancy.
Reports, No. 101 . H.M.S.O., London.

Pitt, D. B., Lewis, I. C., Sims, E., Dods, L., Anderson, N. and Wall, R. (1961). Congenital malformations and maternal rubella: progress report. Med.J. Aust., 1, 881 .

Stuckey, D. (1956). Congenital heart defects following maternal rubella during pregnancy. Brit. Heart J., 18, 519.

Swan, C. (1949). Rubella in pregnancy as an aetiological factor in congenital malformations, stillbirth, miscarriage and abortion. J. Obstet. Gynaec. Brit. Emp., 56, 341 and 591 .

and Tostevin, A. L. (1946). Congenital abnormalities in infants following infectious diseases during pregnancy, with special reference 